\title{
Antoine Ristori. Les Iles de mémoire
}

La Tronche, France: Éditions La Vague à l'Ame, 1990.

\section{D} ans ce recueil superbement préfacé par Serge Brindeau, Antoine Ristori traite de la mémoire en trois parties intitulées: "Mémoire du temps," "De Congénitale mémoire," "Un Jour d'Avril comme aujourd'hui." Dans ce triptyque, le poète remonte les traces du temps en passant par le génie du lieu transcrivant les réactions à un vécu transmis de génération en génération. Mais le sentiment primordial est axé sur l'enfance, la femme, l'amour initié d'abord par la mère pour ce fils unique hanté par l'absence du père parti en voyage en marin à la recherche d'exotisme et de lieux fabuleux. La mémoire retrace alors surtout les départs qui atteignent le niveau mythique, mais aussi les courses folles dans la nature, avec ses "odeurs de chèvrefeuilles" et l'exaspération du "figuier stérile." Cette errance parmi les mythes et la flore exotique éveille la mémoire avec ses rêveries et ses émerveillements.

Mais le temps présente aussi une adversité qui "gèle la mémoire" et "l'oubli génère la vacuité"(16). Le poète tente de transcrire la fugacité de l'image comme l'odeur évanescente, car la fonction du poète est de dire ses éclaboussements de souvenances, d'articuler en verbes et en images les hauts lieux de cette lumière de connaissance sans laquelle la mémoire risque "de s'engorger."

L'errance de la première partie se poursuit dans la seconde, mais cette fois-ci le départ est "vers d'autres solitudes," et le poète est alors en quête de nouveaux symboles "dans la turpitude ou l'enracinement"(33). Les réactions sensorielles déclenchent métaphores et symboles qui permettent au poète de refaire le monde paradoxalement à partir de son "inexpérience." C'est à travers le doute cartésien qu'll s'insinue dans les racines profondes de son moi et de la nuit. Et nous assistons alors à de "cabalistiques méandres / puis [il] se perd dans la touffeur/ où se liquéfient les volontés"(42). Les traces mnémoniques chez ce poète aux prolifiques et capiteuses sensations révèlent leurs mystères par un imaginaire toujours ancré à la lumineuse réalité du souvenir. Et quand "la mémoire se perd 
dans les dédales de l'insignificant"(69), les années sont gloutonnement avalées pour affirmer la sensualité et la ponctuation nécessaire à l'invertébration du poème.

Dans la troisième partie, l'homme trouve "son Amérique:" "De ça de là/ surgit une île/ où il accoste pour un temps/ le temps de reconstituer/ sa provision d'espérance..."(73). Nous avons là cet espoir qui nait non seulement de la nostalgie et de l'innocence des amours enfantines et adolescentes, mais aussi de tous les relais du rêve. La remontée de temps est alors associée indubitablement à la mer, et au monde féminin ainsi qu'à l'abandon souverain des sources primordiales de la vie et du cosmos.

Les courts poèmes de Ristori sont en perpétuelle interrogation de "la mémoire du coeur," et la lueur d'espoir qui nait en face de nous lorsque les ténèbres sont déchirées nous fait vivre et aimer. Ainsi, la remémorisation crée cet espace du rêve et du sourire de la présence et de la décomposition de ces incessantes errances qui engendrent le silence et la parole, le passé et le présent, les échos langagiers et traditionnels, et l'accoutumance au "divin plaisir d'aimer." A travers ce triptyque magnifiquement structuré, le "Chimérique guetteur des cépées de mémoire" (136) double pour ainsi dire le poète-quêteur et réussit à capter ce "rire pour demain" apte à guérir les plaies et l'érosion du moi et du temps . C'est alors que le poète sort victorieux par la maîtrise de ces joyaux poétiques qui ne manqueront pas de lancer à tout lecteur cette nouvelle invitation au voyage dans les frémissements de l'insularité mémorielle. 